\title{
Detection and Estimation of Metanil Yellow \& Congo Red: Carcinogenic Food Colourants, Present in Different Food Samples
}

\author{
Saurjaynee Biswas ${ }^{1 *} \mid$ Nibedita Chowdhury ${ }^{1} \mid$ Ishon Mollick ${ }^{1} \mid$ Deborima Bera ${ }^{1} \mid$ Sandip Kumar Karmakar ${ }^{2} \mid$ Monika
} Paul $^{3}$ | Kakali Bandyopadhyay ${ }^{4}$

\begin{abstract}
${ }^{1}$ B. Tech Student, Department Of Food Technology, Guru Nanak Institute Of Technology, Panihati, Sodepur, Kolkata, India 2Department Of Computer Science \& Engineering, Guru Nanak Institute Of Technology, Panihati, Sodepur, Kolkata, India ${ }^{3}$ Technical Assistant, Department of Food Technology, Guru Nanak Institute Of Technology, Panihati, Sodepur, Kolkata, India

${ }^{4}$ Head, Associate Professor Department of Food Technology, Guru Nanak Institute Of Technology, Panihati, Sodepur, Kolkata, India
\end{abstract}

\section{To Cite this Article}

Saurjaynee Biswas., Nibedita Chowdhury., Ishon Mollick., Deborima Bera., Sandip Kumar Karmakar., Monika Paul \& Kakali Bandyopadhyay. Detection and Estimation of Metanil Yellow \& Congo Red: Carcinogenic Food Colourants, Present in Different Food Samples. International Journal for Modern Trends in Science and Technology 7, 49-55 (2021).

\section{Article Info}

Received on 15-April-2021, Revised on 27-April-2021, Accepted on 01-May-2021, Published on 05-May-2021.

\section{ABSTRACT}

Nowadays adulteration is a social disease which is applied on food to make food more attractive and to gain more profit from it. Along with different processed food products, Spices like Turmeric powder, red chilli powder, etc. provides good nutrition to us until they are treated with some foreign colours or organic colours to make them adulterated, which causes various detrimental effects in physiological system such as heart failure, liver damage, cancer and many more, if people consume them over a certain period of time. Metanil yellow, Sudan red dye, Congo red are such organic dyes which are used abundantly in different spices and processed food products. These dyes are toxic chemicals and could be carcinogenic as well. The presence of all these components can be detected with chemical experiments. This present research study is focused on the detection of adulterants present in sample on the basis of $\mathrm{pH}$ variation of adulterated food sample from the pure one and its estimation by variation of spectrophotometric absorbance with the concentration of the adulterant in the sample. After testing samples with different concentration of adulterants, it has been observed that $\mathrm{pH}$ of samples is gradually increasing with the increase in concentration of adulterants from $O$ to $16.66 \mathrm{gm} / 100 \mathrm{gm}$ present in the sample.

KEYWORDS: Spectrophotometer, Metanil Yellow, Congo Red, pH, Colour Absorbance.

\section{INTRODUCTION}

Day by day the number of food adulteration cases are increasing rapidly and as a result it's became a concern for food safety organizations to trace adulteration in many food materials like honey, Spices, oils, dairy and meat products. [1] Many spices like Turmeric have a history of their use for their medicinal value due to the presence of some chemical compound, (example - Curcumin for turmeric) [2] [3] [4]. For a customer to buy any food product, the first impression is governed mainly by its visual aspect than what impact it has on health after consuming it. Hence the use of synthetic food dyes forms an integral part in food 
industries as an additive to hide the improper conditions of processing and to ensure uniformity and increase its attractiveness in order to achieve financial gain. [5] Metanil yellow, a non-permitted synthetic toxic azo dye, is reportedly used in the adulteration of some food items like in laddo, besan and more significantly in turmeric powder produced by the organized and unorganized sectors [6] [7] [8]. An estimate says that out of 253 food samples that are tested, 58 of them i.e., $20.94 \%$ of total samples contain metanil yellow in which $63.79 \%$ of the metanil yellow positive samples contained adulteration above the maximum permissible limit i.e., above the $100 \mathrm{mg}$ kg- 1 food samples as specified in the Prevention of Food Adulteration Act of India (PFA, 2008). [9] Turmeric powder and red chilli powder has been evaluated with fourier transfer raman and fourier transfer infra-red spectroscopy to detect metanil yellow and congo red samples respectively in it at its lowest possible concentrations, it showed success at 1 and $5 \%$ concentrations respectively. [10] The experimental values i.e., the absorbance values were observed from the Uv- Visible Spectrophotometer (Model: V-630). Metanil Yellow (MY) is a toxic and chief additive adulterant owing to its colour that ranges from yellow to orange and hence is majorly used in turmeric, pulses or sweets as per the colour requirement, in India. [11] Red chilli powder has a long history with congo red named hazardous azo dyederived from benzidine. which is used as adulterants and it has carcinogenic properties [12] [13] [14]. Congo Red has harmful effect even in low concentrations. The harmful effect of azo dye chemicals on human health have been documented. [15][16] Metanil yellow named azo dye is made from diazotized $\bullet$ metanilic acid and diphenylamine. [17]

Hence colorimetric evaluation calls for $a \bullet$ successful way to detect metanil yellow in food $\bullet$ samples.[18] In our study we have utilised double slit UV visible spectrophotometer which uses two beams of light: a reference beam and a sampling beam that passes through the sample. A spectrophotometer can compare the brightness of incident lights by wavelengths. [19]

\section{METHODOLOGY}

In the process, double beam UV visible spectrophotometer was used. Pure metanil yellow solution and pure congo red solution was madd. which was considered to correct the peak or for peak processing. Peak processing is done to achieve the highest peak or highest wavelength for the pure sample known as the absorbance peak.Absorbance (on the vertical axis) is just a measure of the amount of light absorbed. The higher the value, the more of a particular wavelength is being absorbed. After peak processing the samples with different concentrations of metanil yellow and congo red were tested for their espective absorbencies with respect to the peak absorbance. It has been observed that the colour of pure turmeric powder solution will change to magenta colour with the addition of HCL in the presence of metanil yellow (Adulterant) and simultaneously $\mathrm{pH}$ of adulterated turmeric powder will vary with pure turmeric powder. And its $\mathrm{pH}$ and colour will vary the concentration of metanil yellow. And the colour of pure red chilli powder solution will change to deep purple colour with the addition of HCL in the presence of congo red dye (Adulterant) and simultaneously $\mathrm{pH}$ of adulterated red chilli powder will vary with pure red chilli powder. And its $\mathrm{pH}$ and colour will vary the concentration of congo red dye.

\section{Spectrophotometric test:}

\section{1 Reagents Required}

Distilled Water - $30 \mathrm{ml}$ (for each test tube)

Hydrochloric Acid (35\% concentration) - 4 drops Metanil Yellow

Turmeric Powder

Congo red dye

Red chilli powder

\section{II.2 Apparatus Required}

Uv- visible Spectrophotometer, V-630

- Test Tube (6 pcs)

Dropper

Digital pH meter'

\section{II.3 Preparation of Samples}

\section{II.3.1 TURMERIC POWDER AND METANIL} YELLOW

I. Sample 1: (Blank solution)

0 gm Metanil yellow +3 gm Turmeric Powder + $30 \mathrm{ml}$ Distilled Water +4 drop Hydrochloric Acid

\section{Sample 2:}

0.1 gm Metanil yellow +2.9 gm Turmeric Powder $+30 \mathrm{ml}$ Distilled Water +4 drop Hydrochloric Acid 
III. Sample 3:

0.2 gm Metanil yellow +2.8 gm Turmeric Powder $+30 \mathrm{ml}$ Distilled Water +4 drop Hydrochloric Acid

\section{Sample 4:}

0.3 gm Metanil yellow +2.7 gm Turmeric Powder $+30 \mathrm{ml}$ Distilled Water +4 drop Hydrochloric Acid

\section{Sample 5:}

0.4 gm Metanil yellow +2.6 gm Turmeric Powder $+30 \mathrm{ml}$ Distilled Water +4 drop Hydrochloric Acid

\section{Sample 6:}

0.5 gm Metanil yellow +2.5 gm Turmeric Powder + $30 \mathrm{ml}$ Distilled Water + 4 drop Hydrochloric Acid

\section{II.3.2 RED CHILLI POWDER AND CONGO RED DYE}

\section{Sample 1: (Blank solution)}

0 gm Congo red +3 gm red chilli Powder $+30^{\bullet}$ $\mathrm{ml}$ Distilled Water +4 drop Hydrochloric Acid

II. Sample 2:

0.1 gm Congo red +2.9 gm red chilli Powder + $30 \mathrm{ml}$ Distilled Water +4 drop Hydrochloric Acid

\section{Sample 3:}

0.2 gm Congo red +2.8 gm red chilli Powder + $30 \mathrm{ml}$ Distilled Water +4 drop Hydrochloric Acid

IV. Sample 4:

0.3 gm Metanil yellow +2.7 gm red chilli Powder $+30 \mathrm{ml}$ Distilled Water +4 drop Hydrochloric Acid

\section{Sample 5:}

0.4 gm Congo red +2.6 gm red chilli Powder + $30 \mathrm{ml}$ Distilled Water +4 drop Hydrochloric Acid

\section{Sample 6:}

0.5 gm Congo red +2.5 gm red chilli Powder +30 $\mathrm{ml}$ Distilled Water +4 drop Hydrochloric Acid

II.4 Procedure for spectrophotometric test [20]

I. Cuvette is placed into the Spectrophotometer by filling it with blank solution to calibrate Spectrophotometer.

II. After that, the reading of all sample with different concentrations are taken.

III. Same procedure is attained for Sample 3, Sample 4, Sample 5, Sample 6.

IV The wavelengths of the maximum absorbance value is recorded.

\section{pH Test:}

\section{II.5 Reagents Required:}

Distilled Water - $30 \mathrm{ml}$

- Metanil Yellow

- Turmeric Powder

Red chilli powder

- Congo red dye

\section{II.6 Apparatus Required:}

- Digital pH meter

- Beaker

- Glass rod

\section{II.7.1 TURMERIC POWDER AND METANIL}

\section{YELLOW}

1. Sample 1: (Pure solution)

0 gm Metanil yellow +3 gm Turmeric Powder + $30 \mathrm{ml}$ Distilled Water

\section{Sample 2:}

0.1 gm Metanil yellow +2.9 gm Turmeric Powder + $30 \mathrm{ml}$ Distilled Water

51 International Journal for Modern Trends in Science and Technology 


\section{Sample 3:}

0.2 gm Metanil yellow +2.8 gm Turmeric Powder $+30 \mathrm{ml}$ Distilled Water

\section{Sample 4:}

0.3 gm Metanil yellow +2.7 gm Turmeric Powder + $30 \mathrm{ml}$ Distilled Water

\section{Sample 5:}

0.4 gm Metanil yellow +2.6 gm Turmeric Powder $+30 \mathrm{ml}$ Distilled Water

\section{Sample 6:}

0.5 gm Metanil yellow +2.5 gm Turmeric Powder + $30 \mathrm{ml}$ Distilled Water

\section{II.7.2 RED CHILLI POWDER AND CONGO RED $\underline{\text { DYE }}$}

1. Sample 1: (Pure solution)

0 gm congo red +3 gm Turmeric Powder $+30 \mathrm{ml}$ Distilled Water

\section{Sample 2:}

0.1 gm congo red +2.9 gm red chilli Powder +30 $\mathrm{ml}$ Distilled Water

\section{Sample 3:}

0.2 gm congo red +2.8 gm red chilli Powder +30 $\mathrm{ml}$ Distilled Water

\section{Sample 4:}

0.3 gm congo red +2.7 gm red chilli Powder +30 $\mathrm{ml}$ Distilled Water

\section{Sample 5:}

0.4 gm congo red +2.6 gm red chilli Powder +30 $\mathrm{ml}$ Distilled Water

\section{Sample 6:}

0.5 gm congo red +2.5 gm red chilli Powder +30 $\mathrm{ml}$ Distilled Water

\section{8 Procedure for pH test:}

I. Test Tube 1 is taken and $\mathrm{pH}$ is measured with digital $\mathrm{pH}$ meter
II. Similarly, $\mathrm{pH}$ of test tube 2 , test tube 3 , test tube 4 , test tube 5 , test tube 6 are measured and the values are recorded.

\section{RESULTS \& DISCUSSION}

The first table contains the data of the concentration of adulterant i.e., Metanil Yellow added in Turmeric Powder and its corresponding $\mathrm{pH}$. Similarly, the second table contains the data of absorbance of the changed pink to magenta colour from yellow colour on addition of $\mathrm{HCL}$ and the concentration of Metanil Yellow added in Turmeric Powder (sample). The third table is the data set of Concentration of Congo Red in Red Chilli powder and its corresponding $\mathrm{pH}$ values while on the other hand the fourth table comprises the data of absorbance of the changed blue colour on addition of HCL reagent and the concentration of Congo Red used in Red chilli powder (sample). The Total amount of sample taken was 3gm (pure) and gradually the adulterants were mixed in it according to the concentration data given in the following tables thereby maintaining a total weight of $3 \mathrm{gm}$ (pure sample+ adulterant). The amount of adulterants mixed in each of the pure samples are calculated in terms of per $100 \mathrm{gm}$ of the sample as shown below. The absorbance of all the samples is measured at a particular wavelength.

\section{CALCULATIONS}

In $3 \mathrm{gm}$ of pure sample $=0.1 \mathrm{gm}$ adulterant is present

Therefore, in 100gm of pure sample= $(0.1 * 100) / 3=3.33 \mathrm{gm} / 100 \mathrm{gm}$ of pure sample, adulterant is present.

Similarly, the other data were calculated as shown in the tables.

\section{TABLE 1:}

\begin{tabular}{|c|c|c|}
\hline $\begin{array}{c}\text { SAMPLE } \\
\text { NO. }\end{array}$ & $\begin{array}{c}\text { CONCENTRATION OF } \\
\text { METANIL YELLOW IN } \\
\text { TURMERIC POWDER } \\
\text { (gm/ 100gm) }\end{array}$ & pH \\
\hline 1 & 0 & 6.7 \\
\hline 2 & 3.33 & 7.26 \\
\hline 3 & 6.66 & 7.65 \\
\hline 4 & 10.0 & 7.96 \\
\hline 5 & 13.33 & 8.35 \\
\hline 6 & 16.66 & 8.7 \\
\hline
\end{tabular}


TABLE 2:

The following data (absorbance) were observed in the wavelength of $\mathbf{5 1 5} \mathbf{n m}$.

Blank solution taken: $3.33 \mathrm{gm}$ of adulterated sample in $33.3 \mathrm{ml}$ Distilled water.

\begin{tabular}{|c|c|c|}
\hline $\begin{array}{c}\text { SAMPLE } \\
\text { NO }\end{array}$ & $\begin{array}{c}\text { ABSORBANCE } \\
\text { (A) }\end{array}$ & $\begin{array}{c}\text { CONCENTRA } \\
\text { TION OF } \\
\text { METANIL } \\
\text { YELLOW IN } \\
\text { TURMERIC } \\
\text { POWDER } \\
\text { (gm/ 100gm) }\end{array}$ \\
\hline 1 & 3.1 & 3.33 \\
\hline 2 & 4.4 & 6.66 \\
\hline 3 & 4.5 & 10.00 \\
\hline 4 & 4.6 & 13.33 \\
\hline 5 & 4.78 & 16.66 \\
\hline
\end{tabular}

\section{TABLE 3:}

\begin{tabular}{|l|l|l|}
\hline $\begin{array}{l}\text { SAMPLE } \\
\text { NO. }\end{array}$ & $\begin{array}{l}\text { CONCENTRATION OF CONGO RED } \\
\text { IN RED CHILLI POWDER } \\
\text { (gm/100gm) }\end{array}$ & pH \\
\hline 1 & 0 & 4.88 \\
\hline 2 & 3.33 & 5.04 \\
\hline 3 & 6.66 & 5.17 \\
\hline 4 & 10.0 & 5.44 \\
\hline 5 & 13.33 & 5.76 \\
\hline 6 & 16.66 & 5.98 \\
\hline
\end{tabular}

\section{TABLE 4:}

The following data (absorbance) were observed in the wavelength of $760 \mathrm{~nm}$.

Blank solution taken: $3.33 \mathrm{gm}$ of adulterated sample in $33.3 \mathrm{ml}$ Distilled water.

\begin{tabular}{|c|c|c|}
\hline SAMPLE NO & $\begin{array}{c}\text { ABSORBA } \\
\text { NCE (A) }\end{array}$ & $\begin{array}{c}\text { CONCENTRATION OF } \\
\text { ADULTERANTS IN RED } \\
\text { CHILLI POWDER } \\
\text { (gm/ 100gm) }\end{array}$ \\
\hline 1 & 4.1 & 3.33 \\
\hline 2 & 4.3 & 6.66 \\
\hline 3 & 4.3 & 10.00 \\
\hline 4 & 4.5 & 13.33 \\
\hline 5 & 4.5 & 16.66 \\
\hline
\end{tabular}

CONCENTRATION OF METANIL YELLOW IN TURMERIC POWDER (gm/100gm) VS pH Graph

pH

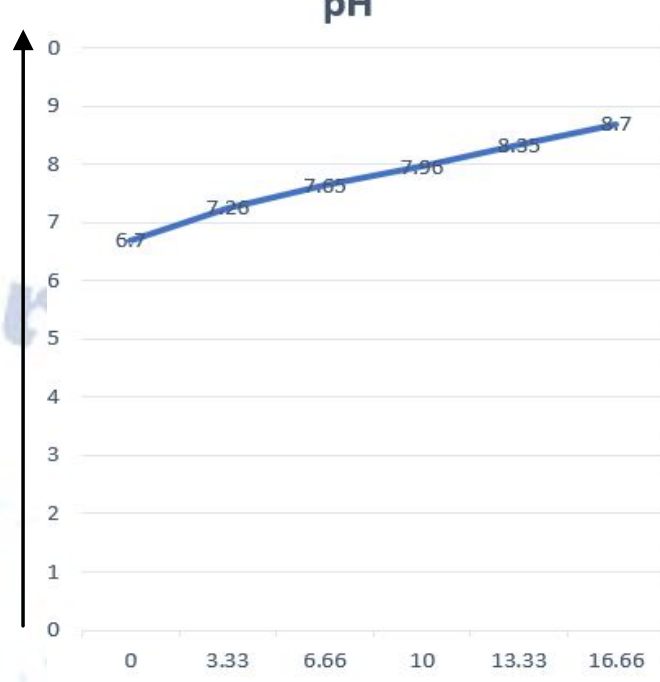

$\mathrm{pH}$

CONCENTRATION OF

METANIL YELLOW

CONCENTRATION OF METANIL YELLOW IN TURMERIC POWDER (gm/100gm) VS ABSORBANCE GRAPH

\section{Absorbance (A)}

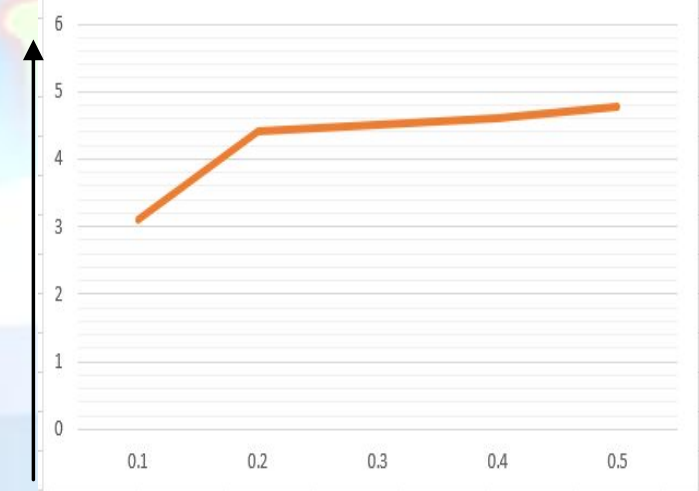

ABSORBANCE
CONCENTRATION OF

METANIL YELLOW 


\section{CONCENTRATION OF CONGO RED IN RED CHILLI POWDER (gm/100gm) VS pH Graph}

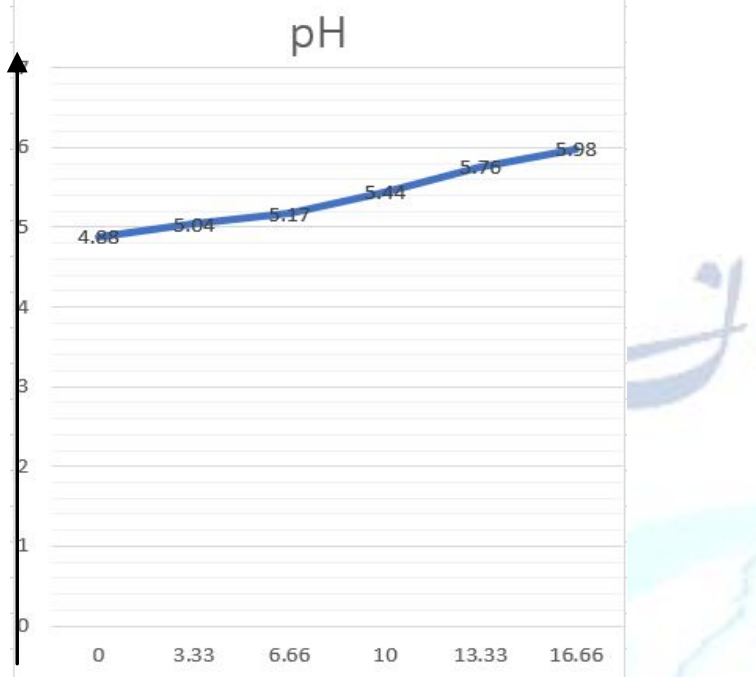

$\mathrm{pH}$

\section{CONCENTRATION OF CONGO RED IN RED CHILLI POWDER (gm/100gm) VS ABSORBANCE GRAPH}

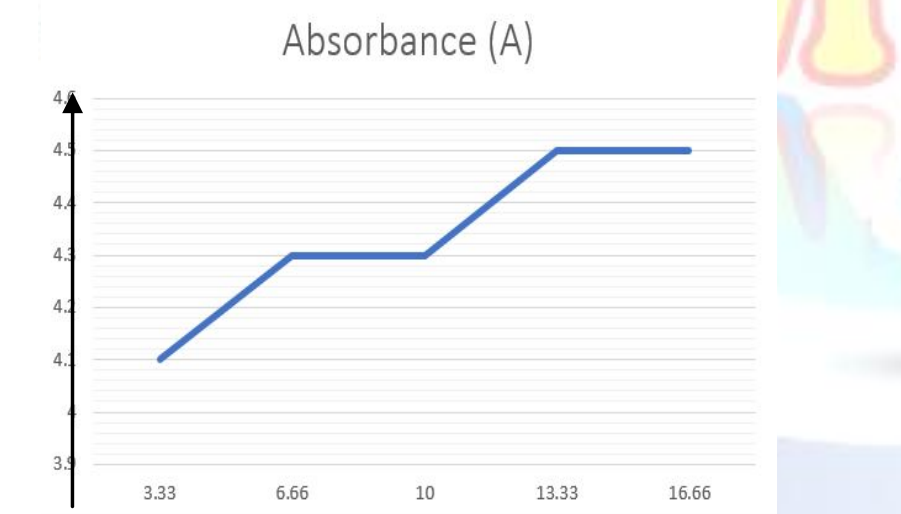

ABSORBANCE

CONCENTRATION OF CONGO RED

\section{CONCLUSION}

Undoubtedly Metanil Yellow and Congo Red are toxic, carcinogenic dyes which is used as an additive and food colorant. Its presence reduces the nutritional value of turmeric powder which is indeed a daily essential need. Despite of being known as a harmful food colorant, it is widely used in many food products as mentioned earlier and greatly affects human health. This research study shows how the value of colour absorbance and $\mathrm{pH}$ of an adulterated sample varies with the concentration of Metanil Yellow added in pure turmeric powder and Congo Red in pure Red chilli powder. The aim of this research study is to make common people aware of the harmful adulterants that are being used in various food products that are being consumed on a daily basis. It is being clearly understood that how the $\mathrm{pH}$ and absorbance varies with the concentration of adulterants added in pure turmeric powder.

\section{REFERENCES}

[1] Lohumi S, Lee S, Lee H, Cho BK. A review of vibrational spectroscopic techniques for the detection of food authenticity and adulteration. Trends Food Science Technol. 2015; 46: 85-98.

[2] R.F.Tayyem, ; D.D. Heath; W.K.Al-Delaimy.;C.L.Rock, Curcumin Content of Turmeric and Curry Powders.Nutr. Cancer 2006, 55, 126-131.

[3] T.Osawa, ; Y.Sugiyama, ; M.Inayoshi, S.Kawakishi, Antioxidative activity of tetrahydrocurcuminoids.Biosci. Biotechnol. Biochem. 1995, 59, 1609-1612.

[4] Tayyem, R.F.; Heath, D.D.; Al-Delaimy, W.K.; Rock, C.L. Curcumin Content of Turmeric and Curry Powders.Nutr. Cancer 2006,55, 126-131.

[5] development of a visible spectrophotometric method for the quantitative determination of metanil yellow in different food samples. parthapratimnath, kaushiksarkar, panchalitarafder and goutampaul* Toxicology Unit, Environmental Physiology Division, Department of Physiology, University of Kalyani, West Bengal, India, Pin741235.

[6] P.P.Nath, K.Sarkar, M.Mondal, G.Paul. Metanil yellow impairs the estrous cycle physiology and ovarian folliculogenesis in female rats. Environ Toxicol 2016;31:2057_67.

[7] S.Dixit,;S.K.Purshottam, ; S.K.Khanna,; M.Das, Surveillance of the quality of turmeric powders from city markets of India on the basis of curcumin content and the presence of extraneous colors. Food Addit. Contam.2009, 26, 1227-1231.

[8] M.Tripathi,;S.K.Khanna ; M.Das. Surveillance on use of synthetic colors in eatables vis a vis prevention of food adulterations act of India. Food Control 2007, 18, $211-219$.

[9] Practice of using metanil yellow as food colour to process food in unorganized sector of West Bengal - A case study, Nath, P. P., Sarkar, K., Tarafder, P., Mondal, M., Das, K. and * Paul, G 1 Toxicology Unit, Environmental Physiology Division, Department of Physiology, University of Kalyani, West Bengal, India, Pin- 741235.

[10] Evaluation of Turmeric Powder Adulterated with Metanil Yellow Using FT-Raman and FT-IR Spectroscopy by Sagar Dhakal, Kuanglin Chao, Walter Schmidt, Jianwei Qin, Moon Kim, Diane Chan.

[11] Detection of synthetic food color "Metanil Yellow" in sweets: a systematic approach Khushboo Kourani, Neeti Kapoor, Ashish Badiye \& Ritesh K. Shukla.

[12] Saleem N, Umar ZN, Khan SI. Survey on the use of synthetic food colors in food samples procured fromdifferent educational institutes of Karachi city. J Trop Life Sci. 2013; 3: 1-7.11.

[13] Chatterjee, S., Chatterjee, B.P. and Guha, A.K., (2007): Adsorptive removal of Congo red, a carcinogenic textile 
dye by chitosan hydro beads: Binding mechanism equilibrium and kinetics. Colloid surface A., 229:146-152.

[14] SHELLEY M. PAYNE AND RICHARD A. FINKELSTEIN* Detection and Differentiation of Iron-Responsive Avirulent Mutants on Congo Red Agar. May 1977, 94-98

[15] Lohumi S, Joshi R, Kandpal. LM, Lee H, Kim MS, Cho H, et al. Quantitative analysis of Sudan dye adul-teration in paprika powder using FTIR Spectroscop. Food AdditContam Part A. 2017;34:1-9.

[16] Miriam Hernández-Zamora, Fernando Martínez-Jerónimo, Eliseo Cristiani-Urbina \& Rosa Olivia Cañizares-Villanueva, Congo red dye affects survival and reproduction in the cladoceran Ceriodaphniadubia. Effects of direct and dietaryexposure (2016), 1832-1840

[17] Available to mankind as it detects carcinogenic metanil yellow in turmeric. from: https://www.merriam_webster.com/ dictionary/metanil\%20yellow .

[18] Schulz, H.; Schrader, B.; Quilitzsch, R.; Preffer, S.; Kruger, H. Rapid classification of basil chemotypes byvarious vibrational spectroscopy methods. J. Agric. Food Chem. 2003,51, 2475-2481.

[19] Y. Yagiz, M.O. Balaban, H.G. Kristinsson, B.A. Welt and M.R. Marshall, Comparison of minolta colorimeter and machine vision system in measuring colour of irradiated Atlantic salmon, Journal of the Science of Food and Agriculture 89 (2009), 728-730

[20] Sagar Dhakal, Kuanglin Chao, Jianwei Qin, Moon Kim, Walter Schmidt, and Dian Chan "Detection of metanil yellow contamination in turmeric using FT-Raman and FT-IR spectroscopy", Proc. SPIE 9864, Sensing for Agriculture and Food Quality and Safety VIII, (2016);98640A

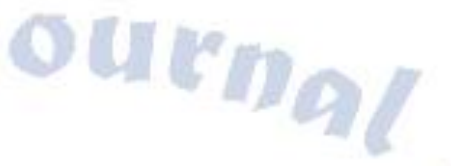

